A N N A L E S Annales de Bretagne et des Pays de l'Ouest

\title{
Élisabeth GONZALEZ, Un prince en son hôtel, Les serviteurs des ducs d'Orléans au XV siècle
}

Hervé Martin

\section{OpenEdition}

Journals

Édition électronique

URL : http://journals.openedition.org/abpo/619

DOI : $10.4000 / a b p o .619$

ISBN : 978-2-7535-1505-5

ISSN : 2108-6443

Éditeur

Presses universitaires de Rennes

Édition imprimée

Date de publication : 30 mars 2007

Pagination : 215-217

ISBN : 978-2-7535-0452-3

ISSN : 0399-0826

Référence électronique

Hervé Martin, « Élisabeth gonzalezz, Un prince en son hôtel, Les serviteurs des ducs d'Orléans au XVe siècle », Annales de Bretagne et des Pays de l'Ouest [En ligne], 114-1 | 2007, mis en ligne le 30 mars 2009, consulté le 22 septembre 2020. URL : http://journals.openedition.org/abpo/619 ; DOI : https://doi.org/ 10.4000/abpo.619

Ce document a été généré automatiquement le 22 septembre 2020

(c) Presses universitaires de Rennes 


\title{
Élisabeth GONZALEZ, Un prince en son hôtel, Les serviteurs des ducs d'Orléans au $X V^{e}$ siècle
}

\author{
Hervé Martin
}

\section{RÉFÉRENCE}

Paris, Publications de la Sorbonne, 2004, 393 p.

1 À la différence de l'Hôtel des ducs de Bourgogne, institution stable entre toutes, qui a laissé une documentation considérable, exploitée avec jubilation par les historiens, l'Hôtel d'Orléans n'était pas des plus faciles à étudier; institution à éclipses, il n'a engendré qu'une documentation fragmentaire et dispersée. Son destin fut en effet singulier : constitué sous Louis 1er entre 1388 et 1392, il fonctionna jusqu'à la mort de ce prince en 1407, en osmose avec l'Hôtel de Charles VI, puisqu'environ un tiers des serviteurs du rival de Jean Sans Peur servaient également le roi. Les années 1410-1415, marquées par la guerre civile entre Armagnacs et Bourguignons, ne furent pas très propices à l'éclosion de la vie de cour ! Et pas davantage les lendemains d'Azincourt et les 25 ans de captivité outre-Manche infligés à Charles d'Orléans. Ce dernier fut contraint de suspendre les gages de ses gens ; son Hôtel se vida dès 1416, à l'exception de la chancellerie et de la trésorerie. Quand le prince revint en 1440, les effectifs de l'Hôtel se reconstituèrent lentement. Au décès de Charles d'Orléans en 1465, la direction de l'Hôtel revint à son épouse Marie de Clèves, décédée en 1483, dont la gestion se signala par l'augmentation du nombre des serviteurs. À partir de 1483, Louis d'Orléans, le futur Louis XII, devint le premier prince de sang. Ses ambitions furent réfrénées par les Beaujeu et par Charles VIII. Emprisonné et privé de ses biens pendant trois ans (1488-1491), il finit par retrouver la direction de son Hôtel, qu'il transforma en 1498, à son avènement, en Hôtel royal. L'étude d'Élisabeth Gonzalez n'embrasse pas cette dernière étape, abondamment documentée. 
2 Les sources, "éparses et fragmentaires ", sont constituées pour l'essentiel par des pièces comptables, corpus énorme mais très disparate, affecté d'un "ventre mou » correspondant à la captivité de Charles d'Orléans. Comble de malheur, une partie des archives a été mise en vente pendant la Révolution et a subi de ce fait une dispersion inimaginable. Loin de se laisser décourager, et comme stimulée par ce défi, l'auteure a entrepris de tirer le meilleur parti de ces bribes pour analyser le milieu social des officiers placés au service du prince et de son entourage, afin d'assurer le train-train de la vie quotidienne et de répondre à tous les besoins d'une Maison princière. Elle a recouru à l'outil informatique pour traiter sa documentation (« une souris et des hommes », dit-elle plaisamment) et, en conséquence, accompagné son ouvrage d'un CDRom renfermant la prosopographie de 300 chambellans, qui se détachent dans la masse des 1700 officiers recensés en l'espace d'un siècle.

3 Très à l'aise dans l'utilisation d'une base de données, E. Gonzalez ne néglige pas pour autant les méthodes traditionnelles. Aussi nous gratifie-t-elle d'une généalogie des ducs d'Orléans et d'une chronologie très complète, intitulée «Les temps forts d'une vie de famille », où elle avance qu'en 1487 « l'entreprise du duc d'Orléans (le futur Louis XII) se confond avec la guerre de Bretagne ", ce qui ramène cette dernière à bien peu de chose! Mieux, la bataille de Saint-Aubin-du-Cormier est censée avoir opposé « indépendantistes bretons et armée royale ». C'est oublier que François II, détenteur d'un État contigu au Royaume de France, était dans son bon droit quand il résistait aux visées annexionnistes des Valois, évidentes depuis le règne de Louis XI. Dans la cosmovision des hommes du $\mathrm{XV}^{\mathrm{e}}$ siècle, un État breton était tout aussi légitime qu'un État écossais, bourguignon ou portugais. On peut se demander si E. Gonzalez n'a pas été victime d'un a priori jacobin ou germanopratin, au nom duquel elle semble oublier que les rangs des « indépendantistes bretons » (ancêtres présumés du FLB ?) abritaient un certain Louis d'Orléans !

4 On ne peut que saluer le souci de rigueur sémantique dont l'auteure fait preuve tout au long de cet ouvrage, en particulier quand elle distingue l'hôtel en tant que résidence du prince de l'Hôtel en tant qu'institution, entendons l'ensemble des personnes placées au service de tel ou tel potentat. Sans être un grand corps de l'État, c'est une institution au plein sens du terme, régie par des ordonnances, corsetée par des rituels complexes, dotée de signes d'appartenance, d'une tradition et d'une mémoire. On peut y voir le cœur de la cour, sans qu'on puisse la confondre avec cette dernière. On observe une même rigueur terminologique quand E. Gonzalez se penche sur les différents émoluments perçus par les officiers de l'Hôtel. Elle nous en donne un précieux lexique (p. 103-104), où les gages ne se confondent ni avec les salaires, ni avec les pensions, pas plus que les livrées avec les livraisons ni avec les défraiements. Chacun de ces termes est accompagné d'exemples précis, puisés aux meilleures sources manuscrites, dont l'auteure détient une connaissance approfondie. D'où, par exemple, des développements éclairants sur les modalités de paiement, où l'on constate que la pratique des ordres oraux a tendance à régresser à partir du début du $\mathrm{XV}^{\mathrm{e}}$ siècle.

$\mathrm{Ne}$ se payant pas de mots, tout en pesant le sens des différents termes en usage, E. Gonzalez estime que la véritable nature d'un office n'est pas révélée par sa définition abstraite, mais par les actes de la pratique et par les documents comptables. C'est en collant ainsi au terrain qu'elle distingue quatre offices essentiels, à savoir ceux de maître d'hôtel, de chambellan, d'écuyer d'écurie et de valet de chambre. Les détenteurs des deux premiers percevaient des émoluments cinq à dix fois supérieurs à ceux des 
derniers cités. Si un chambellan est une sorte d'éminence grise, un valet de chambre n'est pas nécessairement confiné dans un rôle subalterne : il peut très bien se faire une place dans l'administration financière, tout officier étant peu ou prou un factotum.

6 Quel que soit l'attrait d'une lecture au premier degré des sources d'archives, ici abondamment citées pour le plus grand profit des lecteurs et pour l'édification des jeunes chercheurs, aucun historien digne de ce nom ne peut se dispenser de les traiter de façon sérielle, en dressant des tableaux et des graphiques, afin de déceler des tendances plus profondes. E. Gonzalez satisfait pleinement à cette exigence, en nous gratifiant de 18 tableaux (les serviteurs de Louis I ${ }^{\text {er }}$, les officiers de Louis II et de Marie de Clèves, la durée moyenne d'occupation des offices, l'origine géographique des serviteurs etc.) et de 15 graphiques (nombre de serviteurs de l'Hôtel, de chambellans, comparaison avec les effectifs des autres hôtels princiers etc.). Signalons, à la page 275, un tableau très original sur "les ducs d'Orléans et le jeu », qui ravira les lecteurs des travaux de Jean-Michel Mehl.

7 L'auteure fait preuve d'une grande liberté de ton et de beaucoup de sens critique, décochant à l'occasion quelques flèches à tel ou tel auteur pressé. Elle analyse avec beaucoup de finesse le rapport qui se noue au sein de l'hôtel entre le prince et ses serviteurs. Aux gages s'ajoutent les pensions, et à ces dernières les dons et les étrennes. Loin d'être désintéressée, cette munificence ostentatoire et ruineuse tend à attirer des individus en dépendance et à en faire des clients. La relation clientélaire est qualifiée de personnelle, d'inégalitaire et de réciproque. Malgré l'écart existant entre le prince et le serviteur, la relation n'est pas unilatérale, puisque chacun utilise l'autre pour s'élever et que les services rendus par le client lui donnent prise sur son patron. Il faut donc parler d'interdépendance entre l'un et l'autre. Ces considérations anthropologiques confèrent un intérêt supplémentaire à cette contribution solide à la sociographie de l'État du bas Moyen Âge, inaugurée il y a quelques décennies par Raymond Cazelles.

\title{
AUTEURS
}

\author{
HERVÉ MARTIN
}

